\title{
Constant Power Loads (CPL) with Microgrids: Problem Definition, Stability Analysis and Compensation Techniques
}

\author{
Mohammed Kh. AL-Nussairi 1,2 (D), Ramazan Bayindir ${ }^{2}$ (D), Sanjeevikumar Padmanaban ${ }^{3, *}$ (D), \\ Lucian Mihet-Popa ${ }^{4}$ (D) and Pierluigi Siano ${ }^{5}$ \\ 1 Department of Electrical Engineering, College of Engineering, University of Misan, Al-Amarah, \\ Misan 62001, Iraq; muhammed.kh@uomisan.edu.iq \\ 2 Department of Electrical and Electronic Engineering, Faculty of Engineering, Gazi University, Besevler, \\ Ankara 06500, Turkey; bayindir@gazi.edu.tr \\ 3 Department of Electrical and Electronics Engineering Science, University of Johannesburg, Auckland Park, \\ Johannesburg 2006, South Africa \\ 4 Faculty of Engineering, Østfold University College, Kobberslagerstredet 5, Kråkeroy 1671, Norway; \\ lucian.mihet@hiof.no \\ 5 Department of Industrial Engineering, University of Salerno, Salerno, Fisciano (SA) 84084, Italy; \\ psiano@unisa.it \\ * Correspondence: sanjeevi_12@yahoo.co.in; Tel.: +27-79-219-9845
}

Received: 31 August 2017; Accepted: 30 September 2017; Published: 19 October 2017

\begin{abstract}
This paper provides a comprehensive review of the major concepts associated with the $\mu$ grid, such as constant power load (CPL), incremental negative resistance or impedance (INR/I) and its dynamic behaviours on the $\mu$ grid, and power system distribution (PSD). In general, a $\mu$ grid is defined as a cluster of different types of electrical loads and renewable energy sources (distributed generations) under a unified controller within a certain local area. It is considered a perfect solution to integrate renewable energy sources with loads as well as with a traditional grid. In addition, it can operate with a conventional grid, for example, by energy sourcing or a controllable load, or it can operate alone as an islanding mode to feed required electric energy to a grid. Hence, one of the important issues regarding the $\mu$ grid is the constant power load that results from the tightly designed control when it is applied to power electronic converters. The effect of CPL is incremental negative resistance that impacts the power quality of a power system and makes it at negative damping. Also, in this paper, a comprehensive study on major control and compensation techniques for $\mu$ grid has been included to face the instability effects of constant power loads. Finally, the merits and limitations of the compensation techniques are discussed.
\end{abstract}

Keywords: $\mu$ grid; power system distribution (PSD); power electronics; power converters; constant power load (CPL); incremental negative resistance (INR); instability effect of CPL; compensation techniques

\section{Introduction}

The development of electronic switch devices has led to penetrations of power electronic applications in a power system [1,2], advanced control approaches, and more renewable energy sources [3], and on the other hand an increase in energy demands that has consequently led to increased environmental problems such as greenhouse gases being emitted from non-renewable energy sources $[4,5]$; all these factors have contributed to the appearance of new applications in power systems and have taken many forms in modern life [6]. One of these applications is the $\mu$ grid, a new concept for a power system. The $\mu$ grid is proposed to avoid other issues like voltage variations and protection problems when renewable energy sources were placed individually in a power system [7]. 
The $\mu$ grid is a combination of distributed generations, including renewable energy sources and storage devices, and different types and electrical loads interface with a power electronic converter under the control approach in order to achieve proper system operation. The $\mu$ grid can connect to the LV of a traditional distribution network and also can operate as islanded from a distribution system for some cases like a fault in the main distribution grid [7]. From consumers' perspective, the $\mu$ grid contributes to feed different types of load and power quality by supporting voltage for end users and reduces emissions by using clean energy sources [8-10]. In addition, it has improved local stability, increased the efficiency of the system and improved the reliability of the power system by bringing renewable energy sources into reach of consumers [7].

A few years ago, the $\mu$ grid attracted the attention of researcher [11-13]. Those researchers introduced the concept of the $\mu$ grid and solutions to its challenges via stability analysis of the $\mu$ grid in connected and islanded modes [8,14], integration of distributed generations [15-19] and harmonics elimination [20]. The following factors will depict vital issues related to constant power loads (CPL) and their effect on the $\mu$ grid. CPLs affect the power quality of electric system and bring instability, which eventually might lead the system into failure [21-23]. Because of the demand to meet the proper requirements of different loads, $\mu$ grids usually have a large number of power electronic elements for cascade, parallel, driving, and isolation, which are together known as a multi-converter power electronic system $[24,25]$. In control topology, the converter plays a very important role. Some controls needs to apply to converters of $\mu$ grid to maintain the system characteristics (voltage, frequency and power share between distributed generations (DG)) at desired values or regulate these values during transient or sudden increasing of loads $[9,10,26]$. For example, a common control method is droop control in islanded mode [8]. While most control approaches are well designed and satisfy the stability requirements in islanded mode and grid connected for a single converter, the stability of a cascaded convertors system is still a big issue as a result of complex interfacing among converters of the system [1]. As a result, most load converters behave as a constant power load. Many solutions have been proposed to mitigate or solve this problem, but these solutions have some limitations and also focus on DC-DSP. In this paper, the major compensation techniques and their control approaches used to face CPL instability effects in the $\mu$ grid and power system distribution will be considered.

The following topics will be addressed: Section 2. Concept of $\mu$ grid; Section 3. Definition of constant power load and its sources and effects; Section 4. A brief review of major control and compensation techniques to mitigate the instability effects of constant power loads; and Section 5. Discussion of results and conclusions.

\section{The $\mu$ grid}

The $\mu$ grid is defined by the Consortium for Electric Reliability Technology Solutions (CERTS) in the USA as "An aggregation of loads and micro-sources operating as a single system providing both power and heat". Another definition set by the European MICROGRIDS project is "a low voltage distribution network comprising various DG, storage devices and controllable loads that can operate interconnected or isolated from the main distribution grids" [26-28]. The $\mu$ grid was introduced as an efficient solution to guarantee the reliable operation of distribution generating (DG) when DGs operate in connected mode or islanded mode $[6,25,29,30]$. $\mu$ grid is a tiny power system consisting of a set of different distributed generations, loads, power electronic elements, and transmission systems, as shown in Figure 1.

Distributed generations cover renewable energy sources like a PV system, a wind power system or micro-turbine systems, and storage systems like a fuel cell system [8,28,31,32]. The output energy (magnitude and form of current and voltage) from distribution generating is not suitable for use by consumers because it is affected by environmental conditions and the DGs cannot connect directly to buses of the distribution grid $[7,9,10,31,33,34]$. Therefore, DGs connect to a common bus by the interfacing converters to convert the output power (voltage and current) utility-grade for an AC or DC system with the desired magnitude voltage and current, and frequency for an AC system [31,34,35]. 
The concept of the $\mu$ grid becomes suitable and attractive due to power electronic converter facilities, in which it overcomes some difficulties found in the traditional AC network like power loss in transformers and long transmission lines, and high voltage transformation [33]. In islanding mode, the response of the $\mu$ grid for the regulation of common bus is by making a one power converter master and others slaves or making all sources take part in the regulation and of transfer energy to the loads [13].

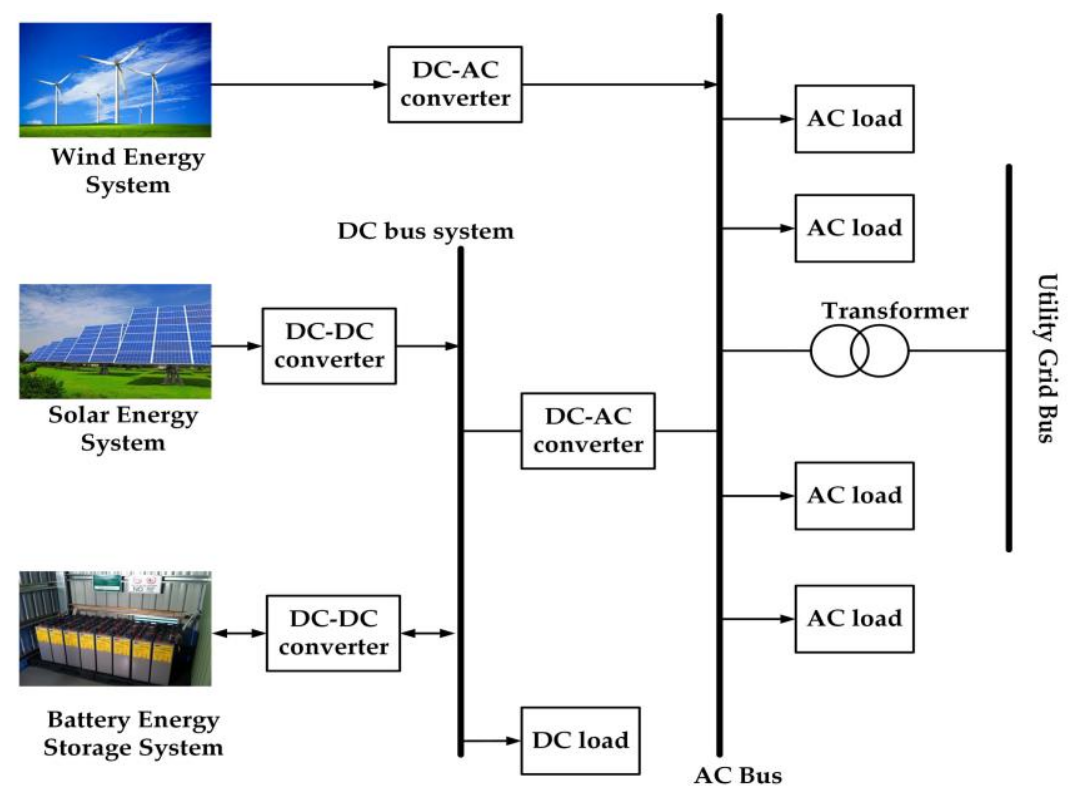

Figure 1. Typical hybrid $\mu$ grid configurations.

According to [3,18], loads in the electronic power system are divided among three groups: constant voltage load, constant current load, and constant power load. The first group sinks the constant value of voltage from the source regardless of the current. This type includes conventional resistive loads such as heating equipment, and inductive loads [19]. The constant current load draws a fixed current under wide variations of voltage source and has transducer and arc lamp as examples. The last type is CPL and will be the subject of this research. More details and examples about constant power loads are given in the following sections. The connection between elements of $\mu$ grid, like the traditional grid, can be achieved by ring or radial connections [9].

\section{Constant Power Loads}

\subsection{Problem Definition}

Some power systems need a multiconverter to provide the system with various power and voltage forms [22,36,37]; these are known as multiconverter power electronic system [24,25]. This type of system consists of large number of power electronic devices in parallel, cascade, stacking and splitting configurations for loads and source to achieve proper required operation [24]. One multiconverter power electronic type is the cascade system of a converter, shown in Figure 2, which consists of a source converter that provides the regulated voltage to the system (others are called upstream converters or voltage regulators) and a second convertor that converts the line voltage to proper value and frequency for each load [21,38]. A multiconverter has a large variety of operation instructions because of the interconnection of components of the multiconverter [22,36,37]. 


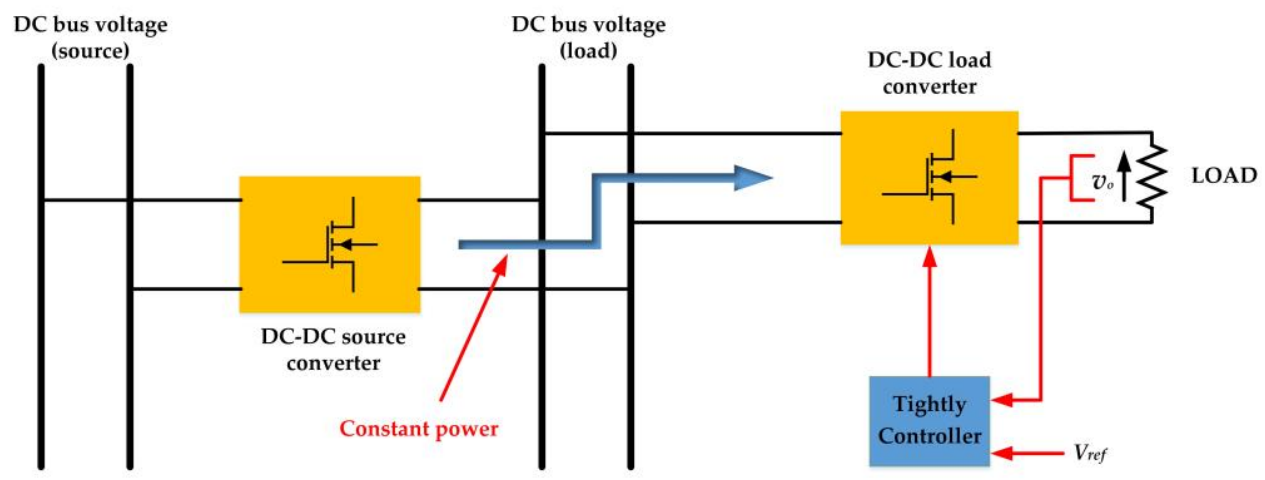

Figure 2. DC-DC converter with resistive load behaves as a constant power load (CPL).

The load converters (second stage of multiconverter) tend to display the properties of a constant power load when control is applied tightly [22,36,37], which means a converter has a fast response and low output ripple [37]; therefore, the converter behaves as the CPL with their control bandwidth [39]. Constant power loads (CPL) means that the output power of the convertor is constant, i.e., the output voltage drops when small variations occur in the current value (increasing current amount), which means that when neglecting the dissipated power into the circuit, the output power and input power are equal [22,36]. In fact, the converter behaves as a CPL when it has closed loop control and as a resistive load in open loop as in Figure $3[1,40]$. The power electronic converters tends to have CPL properties if them output voltage is bigger than voltage reference $\left(V_{c}\right)[21,22,30,41-43]$; in other word, the converter behaves as resistive load at start-up but as a CPL when it exceeds the value of voltage reference $\left(V_{c}\right)[30]$.

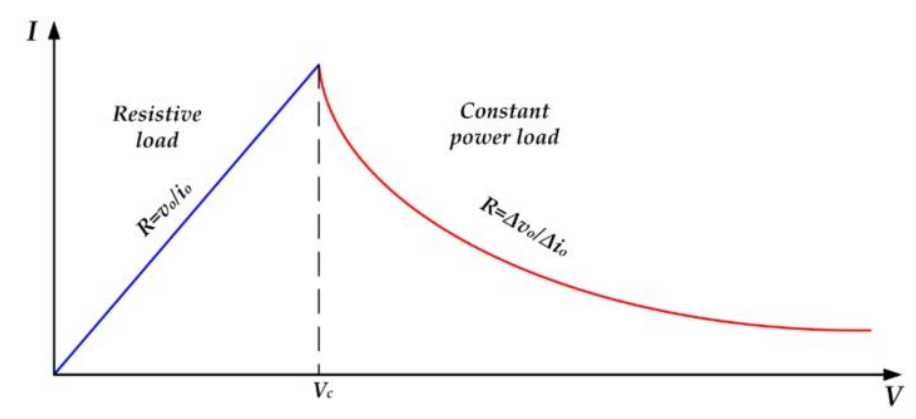

Figure 3. V-I curve of load converter.

Many loads like motor drives or electronic loads with tightly regulated controllers behave as a constant power load [22,36,37]. Figure 4 is an example of CPL, where the motor is driving by DC-AC inverter, and the inverter is tightly regulated to control the speed. When the load is rotating, the motor will have one to one of torque-speed characteristics and the relationship between the speed and torque is linear.

For a linear relationship, each value of speed has only one corresponding value of torque. Therefore, the power equals the multiplication of torque and speed, which will be constant [22,36,37].

Another example is a DC-DC converter, which feeds the electric load and is tightly controlled to maintain an output voltage fixed on the load [22,36,37], as shown in Figure 2. The power of the load is constant when there is a linear relationship between voltage and current. 


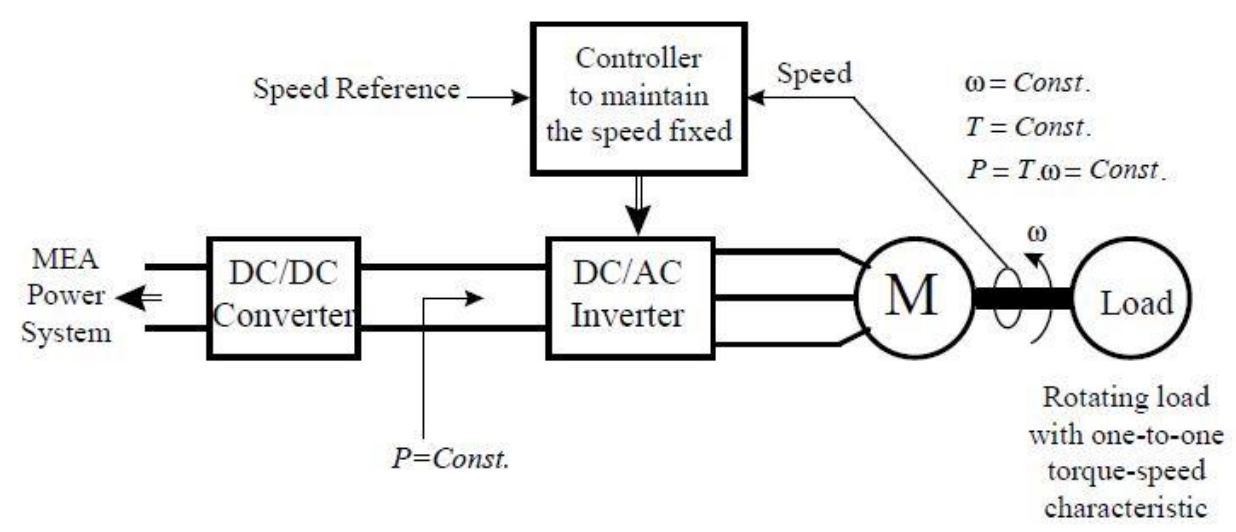

Figure 4. DC-AC inverter that presents a constant power load characteristic.

In CPL, the output power will be equal to the input power, neglecting power losses in the system. As in [44], the mathematical model of CPL can be derived as follows:

$$
P_{\text {in }}=P_{\text {out }}=\text { cons. }
$$

The differential change in the input power can be expressed as:

$$
\partial P(v, i)=0=v d i+i d v .
$$

The input incremental resistance $r_{\text {in }}$ can be defined as:

$$
r_{i n}=\frac{d v}{d i}=-\frac{v}{i} .
$$

The negative sign that appears in Equation (3) means that the CPL characteristics can be explained by the negative slope of the V-I curve shown in Figure 5 [45]. The CPL has inherent incremental negative resistance (INR). There is more than one way to realise a mathematical formula of INR [22]. This instability effect of NIR does not discuss when the converter is designed but in a multiconverter the level should be taken into consideration. This phenomenon will impact the stability of $\mu$ grid and make the LC filter oscillatory [46].

\subsection{The Negative Incremental Resistance (NIR) of the Constant Power Loads (CPL)}

The converter that is used for open loop or bad close loop control does not have constant power load properties. The CPL consumed a fixed power and Negative Incremental Resistance with its bandwidth control. In the CPL, the relative rate of change between the voltage and current is negative $(d v / d i<0)$, but the instantaneous value of impedance is positive $(V / I>0)[21,22,36,37,42,43,47,48]$. The stability point of a system means; the system will return to a specific point if any disturbance occurs. The steady state point in a system that includes the CPL is obtained when the CPL voltage is equal to the voltage source. At this point, the system will be stable. Nevertheless, if any disturbance occurs, the system cannot return to this point $[49,50]$.

This can be understood as follows: if a small disturbance makes the load voltage less than the voltage value of the stable point then the load current will be bigger than the load current at constant power of the load and result in the filter capacitor being discharged. Thus, the load current will increase to make the power constant and at the same time the voltage will decrease. If a system does not have a proper control to prevent this phenomenon during transient or any small disturbance, the voltage will be zero and the current will go to infinity. Previously the system behaved as a feedforward. Now if there are any changes in the voltage of the source converter (i.e., decreasing), the load converter will 
increase the duty cycle to regulate the voltage, which means the current will increase to maintain constant power [49].

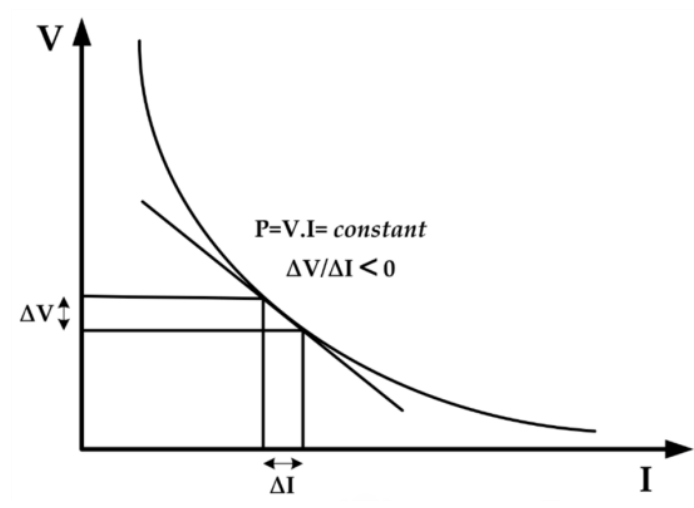

Figure 5. Negative impedance behaviour of constant power loads.

Figure 6 includes the connection of CPL with the parallel capacitor [22]; the state equation of the circuit can be written as follows:

$$
v_{c}=\frac{P}{i} \text { and }-i=C \frac{d v_{c}}{d t} .
$$

The solution of these equations gives

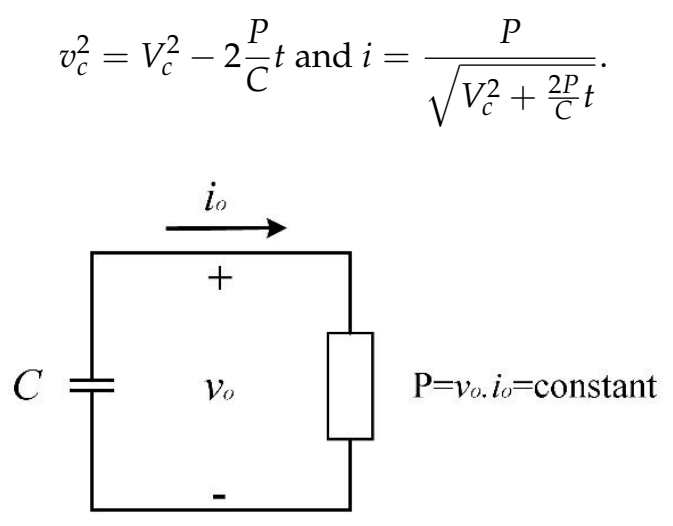

Figure 6. A constant power load parallel with a capacitor.

The solved equations show the circuit that exists from the CPL and parallel capacitor is unstable because as $\left(t=V_{c}^{2} C / 2 P\right)$ the voltage goes to zero and the current goes to infinity. Therefore, the CPL is unstable with a parallel capacitor. The equilibrium point of the circuit is when voltage of CPL is equal to the source voltage. In other cases, the system loses its stability and cannot restore the steady state because the INR of CPL and voltage will go to infinity as the current goes to zero and vice versa.

\subsection{Negative Incremental Resistance Effects on the $\mu g r i d$}

As mentioned previously, a system that has a CPL could be unstable. This instability is produced by the interaction between the power system structure and the negative impedance created by the CPLs. Negative incremental impedance impacts the power quality of the system and can lead to system voltage oscillations or even collapse, and reduces system damping. These system voltage oscillations put additional stress on the components and may lead to the system failing or its components being damaged $[23,25]$.

Most often, a filter, which usually consist of inductor (L) and capacitor (C), place after a pulse width modulation power converter to minimise the input current harmonics. Because of the small 
value of the resistance of the LC filter, a large transient oscillation can occur between $L, C$ when operating conditions change suddenly [51].

CPL instability will occur when the applied control on a system is tightly regulated and has a closed loop. Feedback controllers of the closed loop depend on the process output (voltage or power). The NIR of CPL makes the damping of the input LC filter of multiconverter system negative and the LC filter oscillatory [52]. Therefore, this oscillation at the output will make the system unstable. Thus, the instability effects of CPL (INR) can be summarised on any power electronic system as mentioned in $[2,25]$ as follows: CPL reduces the equivalent resistance of the system, causes a high inrush current as the voltage builds up slowly from its initial value, makes the system poorly dampened and impacts on the stability $[37,38,47,53,54]$, which causes limit cycle oscillation in the DC bus voltage and currents and may lead to voltage collapse $[23,53,55]$.

\section{Compensation Techniques Used to Combat the Instability Effects of CPL}

Because of the non-linearity and time dependency of converters' operation and the incremental negative impedance effects of constant power loads, classical linear control methods (like a conventional proportional integral PI controller) have stability limitations around the operating points and are not applicable to these systems. Therefore, digital and nonlinear stabilising control methods must be applied to ensure large-signal stability [21,22,36,42,48,56,57]. Compensation Techniques of the instability of CPL can be achieved by adding an extra element like passive elements or devices to the power system, or redesigned the control loop of a source or load converter [25,58]. The following sections summarise the methods used to compensate for the instability effects of INR in previous years.

\subsection{Passive Damping}

Passive damping is a simple method to increase the damping of a system by adding passive elements; which are contain resistance $(\mathrm{R})$, inductor $(\mathrm{L})$ and capacitor $(\mathrm{C})$, to the input filter of the system, as described in $[39,59]$. The authors introduced three methods for passive damping by adding $R C$ and $R L$ in parallel with input filter and $R L$ in series. In [60], the method used is adding only $R$ in parallel with the L-filter. As in [39], the method proposed here to stabilise the system is minimisation of the peak output impedance of the filter by adding a passive damping (passive elements) circuit to the LC filter. The stability of the CPL system requires the impedance ratio $Z_{d} / Z_{1}$ to meet the Nyquist stability criterion, or alternatively, the characteristic polynomial of $\left(1 /\left(1+Z_{d} / Z_{1}\right)\right)$ to meet the Routh-Hurwitz criterion. The paper introduced three methods of passive damping: (a) $R C$ parallel damping; (b) $R L$ parallel damping; (c) $R L$ series damping, as shown in Figure 7.

These methods were tested by the authors, who obtained the following results: the best method is adding $R C$ parallel damping because large CPL compensation by $R L$ parallel damping is needed to minimise the L-filter, which is undesirable. $R L$ series damping can compensate only if $R_{\mathrm{CPL}}>(3 L / 2 C)^{1 / 2}$ and the dissipated average power is the biggest in $R L$ series damping and $R C$ parallel damping and the smallest in $R L$ parallel damping.

Another method to achieve passive damping was developed by [61,62]. The effect of the converter parasitic, which includes the resistance of the ' $\mathrm{ON}$ ' switch, inductor and diode in the presence of CPLs, is analysed in detail under both converter operation modes; continuous conduction mode (CCM) and discontinuous conduction mode (DCM). Also, design recommendations are presented to face instabilities of CPL in a DC distribution system with a pure CPL and a combination of CPL with resistive loads.

This method is simple to implement. It does not require the addition of any control terms to the control loop of the system. By using this method, the stability of the system is achieved. The efficiency of the system is decreased because there will be a greater power loss when using this method. It will be expensive when passive elements are added, especially capacitors. This method in $[39,59]$ is valid for small disturbances [60]. 


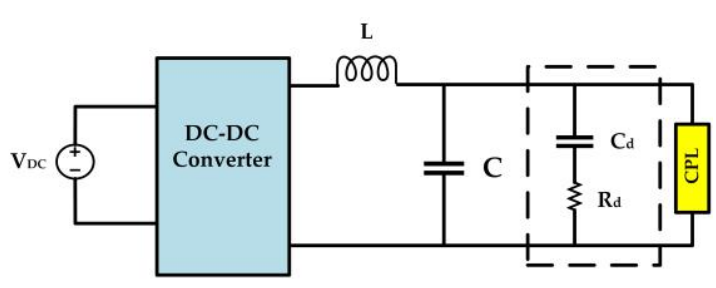

(a)

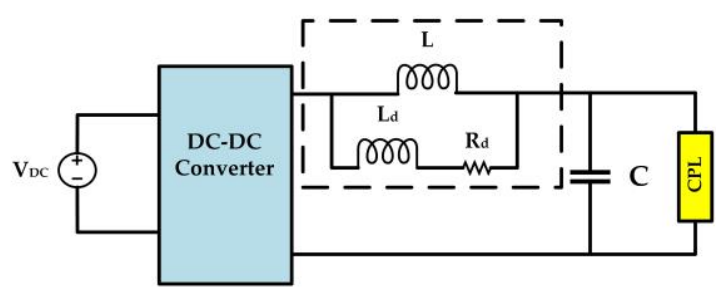

(b)

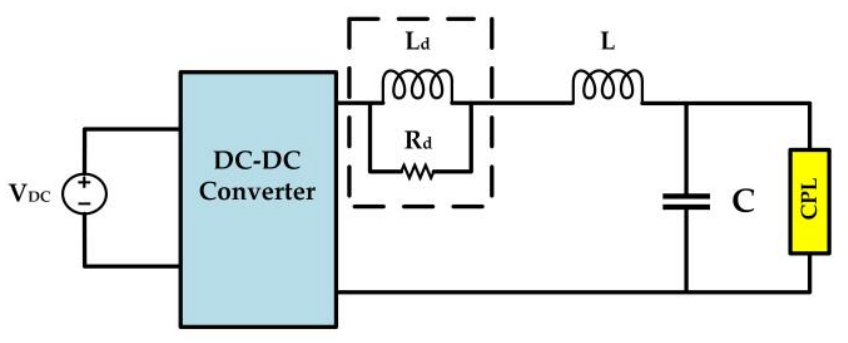

(c)

Figure 7. Passive damping techniques: (a) $R C$ parallel damping; (b) $R L$ parallel damping; (c) $R L$ series damping.

\subsection{Active Damping}

Active damping, another solution to the instability problem introduced by INR, involves a modification control loop by creating a damping effect of passive damping or modifying the DC bus capacitance. Also, it can be achieved by adding a device that injects a compensating current [63]. The active damping can be done by three methods [2]. The first is source-side active damping. The compensation at the source subsystem by active damping aims to add loop in loop control to improve the output impedance of feeder converter to satisfy the impedance stability criterion. This type is impossible to apply to a system when the input stage is LC or uncontrolled rectifiers. To overcome the instability effect of INR, the CPL side Active Damping is considered when the source subsystem of a CPL is LC filter. The concept of this method is achieved by injecting a current or power into the CPL control loops to modify the input impedance $Z_{i n}$, such that Middlebrook's stability criteria are satisfied $[2,25]$. The third is adding auxiliary device that injects the desired compensating current within operation range system.

Virtual impedance or resistance is one method of active damping introduced by researchers in $[34,45,54,63-68]$. Active damping, by adding virtual resistance, achieves the improvement transfer function of a system and forces the movement of the poles towards stable region (left half of s-plane). It guarantees that any extra power does not dissipate into the system $[45,63,64]$, as in Figure 8 a. In fact, the virtual resistance makes the output impedance of the source converter less than its maximum value [58]. The output voltage $V$ is measured and controlled to track the reference voltage $V_{\text {ref }}-$ $i_{L} R_{e q}$ instead of a constant voltage reference, as shown in Figure $8 \mathrm{~b}$. The new reference value will vary according to the value of the load current and hence produces the equivalent function of adding physical resistor $R_{e q}$. [45,64]. In [63] the authors presented a new method to overcome the problems of CPL by adding virtual resistance, which will affect the series resistance with an inductor to feedback control system. In [34] the authors introduced the virtual impedance as series-connected resistance and inductance and two types of stabiliser; one is based on capacitor voltage feedback, and the other is based on inductance current feedback for achieving a virtual impedance method and a model including a droop control index. In [66] an additional proportional voltage feedback control is inserted with virtual resistance to improve the system performance and overcome the disadvantages which 
produced from adding a large value of virtual resistance. One of these advantages is the region stability of virtual resistance will narrow as the output power increases [2].

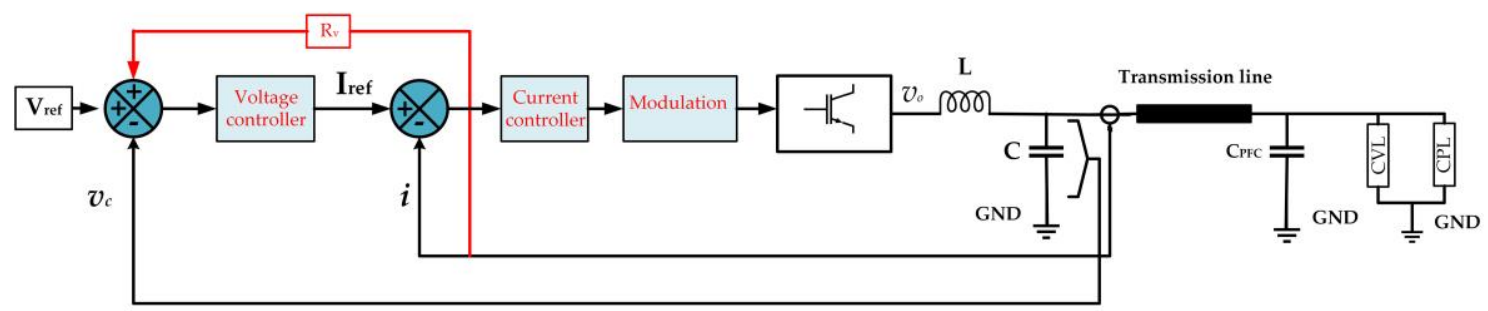

(a)

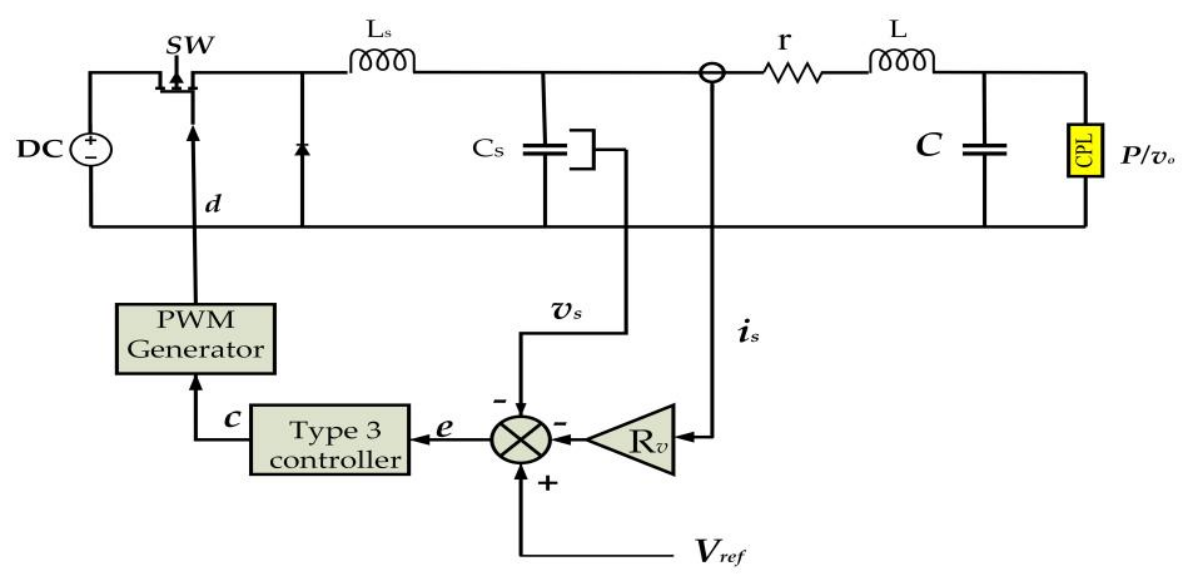

(b)

Figure 8. The proposed active-damping method based on adding virtual resistance: (a) [45]; (b) [64].

In [69] a feed-forward control with extra elements to improve the stability of hybrid electric vehicles (HEV) with CPL is introduced. The purpose of this method is changing the impedance of the load converter to match the impedance of the source. The changes are approved by the impedance frequency and analysed by a low pass filter, and negative impedance can be eliminated by adjusting the virtual resistance in the control loop. In [70], active damping was achieved by modifying the duty ratio of the converter by using a first-order high-pass filter with a corner frequency and high magnitude.

In [71,72], the authors presented an input-resistance compensator to eliminate the instability of INR in a system that has a power electronic brushless DC motor drive with constant power-load characteristics, as shown in Figure 9. The strategy is to feed a portion of the changes in the DC-link voltage into the current control loop to modify the system input impedance in the mid-frequency range and thereby to damp the input filter. The input-resistance compensator is a high-pass filter with corner frequency and high frequency magnitude. Its operation depends on the DC link voltage. the current output is a current (the stabilising signal) that will act with the speed control loop to give a current reference to the control motor current by high frequency pulse width modulation (PWM) with a duty cycle determined by the PI controller. At steady state, the authors assumed the output of IRC will be zero if there is a change in the DC link voltage but if the output of IRC is non-zero, then a signal will be generated to modify the motor current and the inverter input impedance, damp the DC-link oscillations. 


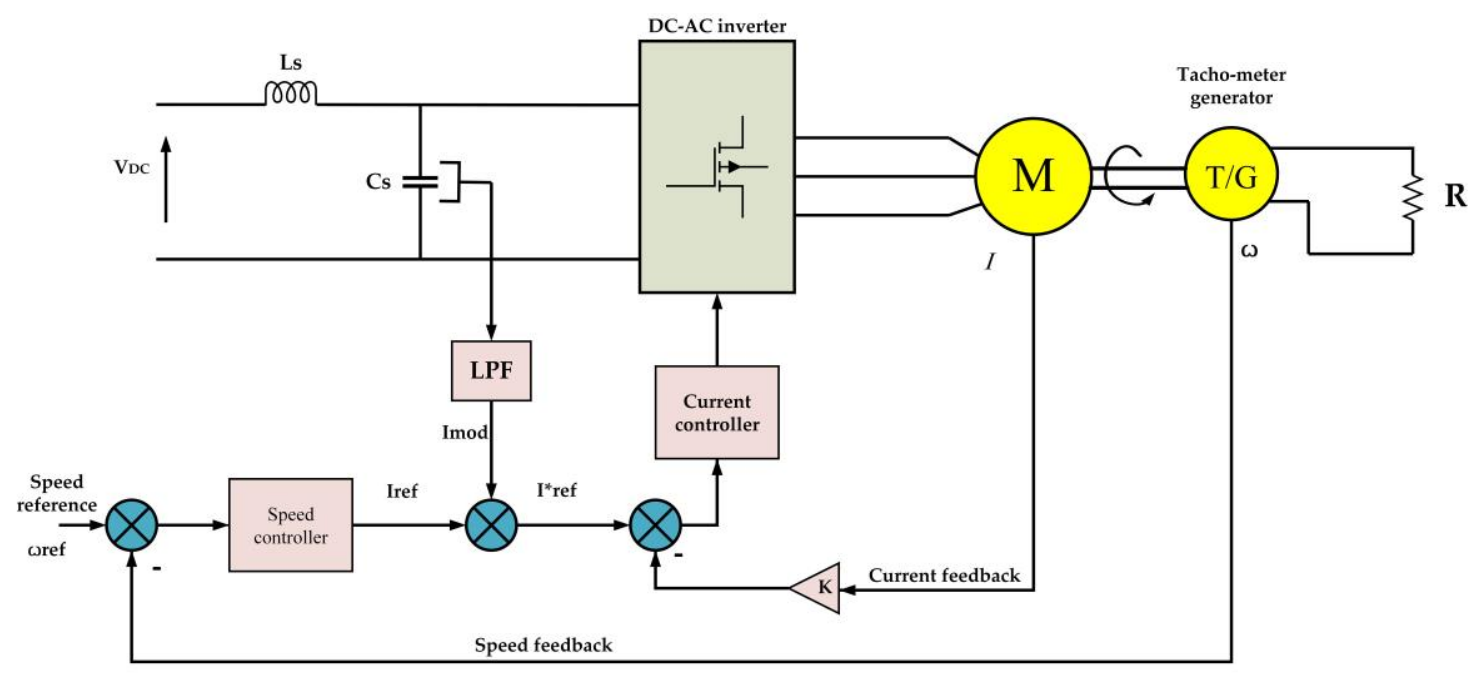

Figure 9. Negative input-resistance compensator of motor drive.

In [23] a new device called a solid state defender (SSD) is added between the load converter and source to protect the system and its elements against the fault and instability phenomena of INR and prevent the system from failure or damage of components. The SSD works as a power buffer in the bus fault case and transfers the stored energy in a capacitor to feed the load and current limiting in load fault by limiting output current. On the other hand, it works as an impedance transformer to address the oscillation and transience produced by INR. The SSD improves the power quality of the system and eliminates the oscillations caused by the negative incremental impedance characteristic of loads. Active damping has received interest from researchers [34,45,54,58,63-68,73]; however, active damping causes effective performance but only compensates for limited values of CPL [25] and sometimes causes the output voltage to drop, as in [63].

\subsection{The Space Pole Placement Control}

The Space Pole Placement Control is used to shift the pole of the system from RHP to LHP of the s-plane. A new pole location must be chosen to satisfy the characteristic equation of the closed loop system to make the system is stable. According to the paper, this method can be achieved by multiplying the specific gain (calculated by Ackermann's formula) by the state variables (inductor current and voltage capacitor) in closed loop control. However, the result is subtracting from the reference voltage. The generated switch pulse has been produced from comparison of the difference with the tooth signal as shown in Figure 10 [49]. This method needs to represent all the state variables in a control loop [2,49].

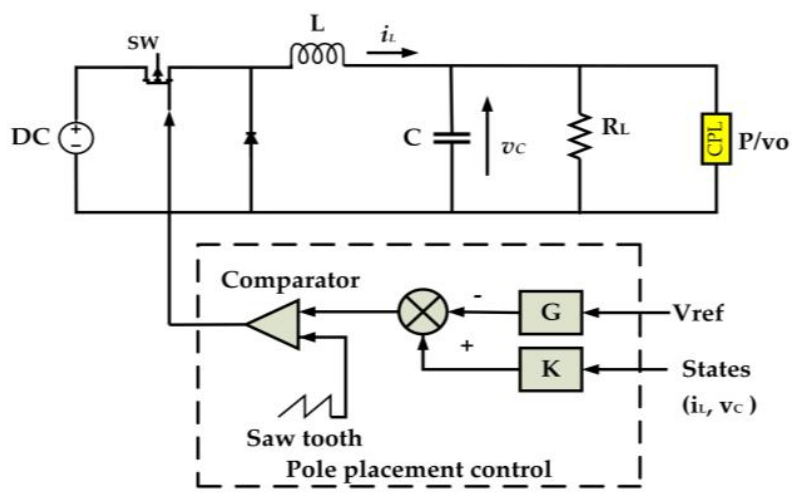

Figure 10. Pole placement control. 


\subsection{Pulse Adjustment Control Technique}

The papers $[43,48,56,74]$ presented pulse adjustment control technique as a new control method to damp the instability caused by CPL with a DC-DC converter in vehicular systems. The pulse adjustment control is a digital control that drives the PWM control. The adjustment controller regulates the output voltage by generating high and low power pulse through comparing the output voltage and reference (desired) voltage and sending this pulse to the PWM. For output voltage (capacitor voltage) less than the reference voltage the controller will increase the transferred energy from input to output. The CPL will consume the required energy and voltage will be increased as a result of charging the capacitor with the remaining power as in Figure 11. This paper presented the same controller as in [48] to provide the buck-boost converter but in discontinuous conduction mode (DCM). The drawbacks of this technique are high output voltage ripple, noise and the sub-harmonic presented the output voltage, although it has fast response times and a robust controller [75].

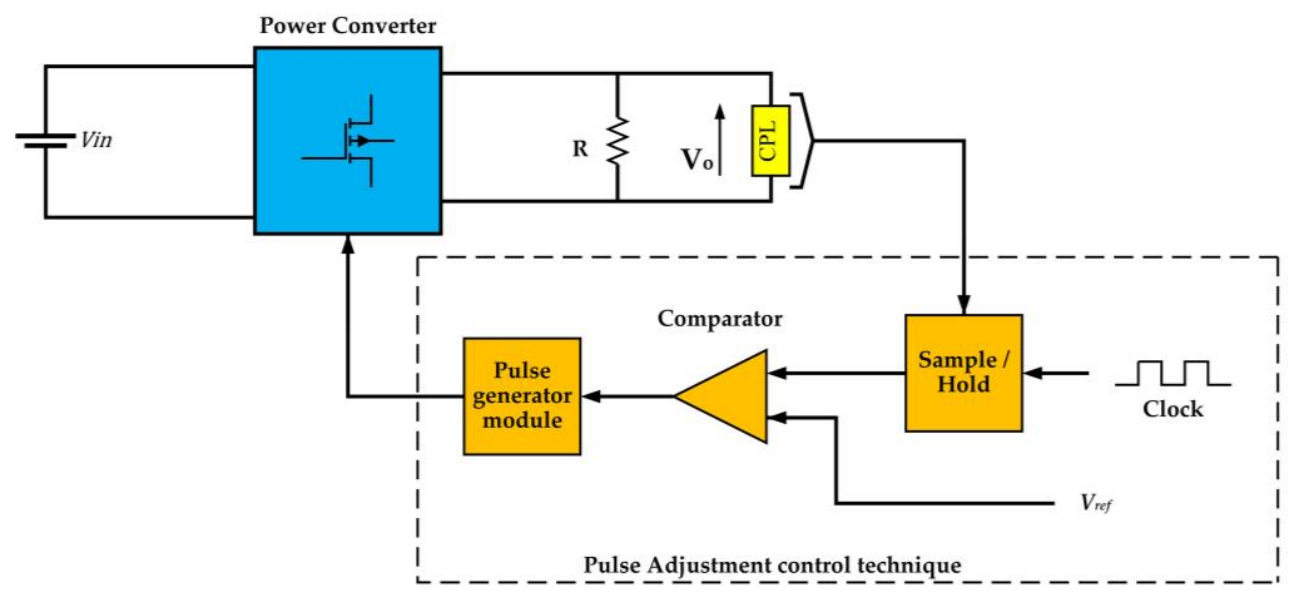

Figure 11. Block diagram of the pulse adjustment control technique.

\subsection{Sliding Mode Control}

Sliding mode control has been used to address the instability effects of INR in the literature $[21,25,36,57,76-82]$. The aim of this controller is to control the output power of a DC-DC converter with CPL by setting the reference value of power and comparing it with the measured output power of the DC-DC converter [21,36]. The proposed sliding mode control outputs a duty ratio, which is used to generate pulse width modulated (PWM) gate signals for the DC-DC converter.

This controller improves signal stability and dynamic response; however, it is sensitive to large changes in load [36] and the controller is effective at a high voltage above 400 volts but has disturbance at low voltages [57], which means the output voltage is not fixed.

In [36], the authors tested the CPL with a parallel capacitor by using a series inductor and a buck converter. The circuit is unstable: instability will quickly appear in the buck converter and other instability will occur within a short time. Due to the instability of CPL that occurs within an interval smaller than the switching time, there is a need to increase the switching frequency of $L$ and $C$. The paper presented the sliding mode as improving the large signal stability and dynamic response of the buck converter. The objective of the control system in DC-DC converters with constant power loads is to control the output power. $\mathrm{P}_{\text {out }}$ is the output power and $K$ is the output power reference.

1- Buck converter with CPL in Figure 12 can be written using the state space averaging method:

$$
\dot{x}_{1}=-\frac{1}{L} x_{2}+\frac{d}{L} V_{i n}
$$




$$
\dot{x}_{2}=\frac{1}{C} x_{1}-\frac{1}{R C} x_{2}
$$

where $x_{1}$ and $x_{2}$ are the moving average of the inductor current and the output voltage of the converter, respectively.

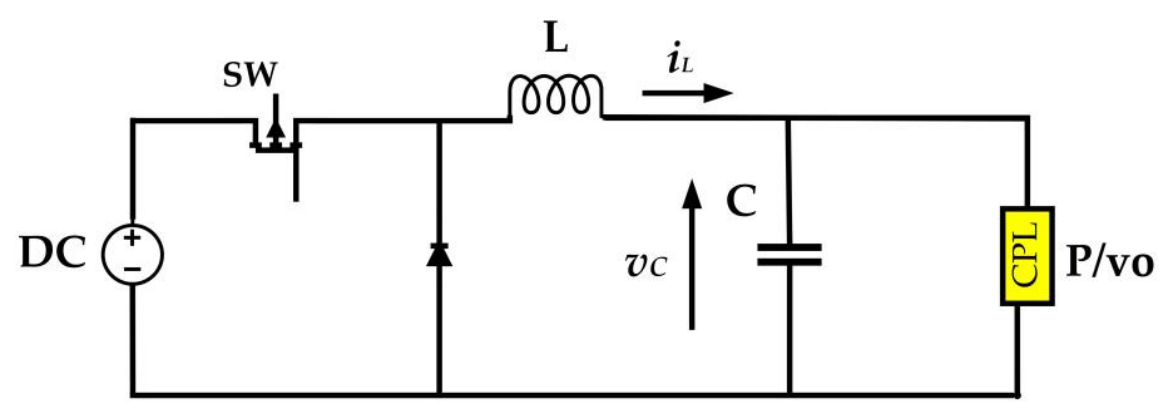

Figure 12. DC-DC Buck converter feeding CPL.

2- The authors in [36] assumed that $K$ is the output power reference and forced the output power to be equal to this value by sliding mode control, as follows:

$$
\begin{gathered}
\frac{\partial P_{\text {out }}}{\partial t}<0 \forall P_{\text {out }}>K \\
\frac{\partial P_{\text {out }}}{\partial t}>0 \forall P_{\text {out }}<K .
\end{gathered}
$$

3- The following equation satisfies the above requirements:

$$
\frac{\partial P_{\text {out }}}{\partial t}=-\lambda \cdot\left(P_{\text {out }}-K\right),
$$

where $\lambda$ is a positive real number and is called the convergence factor.

4- $\quad$ The objective of this paper is to obtain the duty cycle for the buck converter by combining Equations (1) and (3);

$$
d(t)=\frac{\frac{1}{L} x_{2}^{2}-\lambda\left(1-\frac{\lambda \cdot R C}{2}\right)\left(\frac{x_{2}^{2}}{R}-K\right)-\frac{1}{C} \cdot \frac{1}{x_{2}^{2}}\left(\frac{\lambda \cdot R C}{2}\right)^{2}\left(\frac{x_{2}^{2}}{R}-K\right)^{2}}{\frac{x_{2} \cdot v_{\text {in }}}{L}} .
$$

In [77] the stable sliding surface (s), shown in Figure 13a, is designed to obtain system control law $(\mathrm{u})$ is to meet the system stability requirements with reference values for the inductor current and capacitor voltage. The stable sliding surface (s) can be written:

$$
\mathrm{s}=\mathrm{x}_{1} \cdot \mathrm{x}_{2}-\mathrm{x}_{1 \mathrm{r}} \cdot \mathrm{x}_{2 \mathrm{r}}+\mu\left(\mathrm{x}_{2}-\mathrm{x}_{2 \mathrm{r}}\right)
$$

The control law $(\mathrm{u})$ can be written:

$$
u \frac{1}{2}(1-\operatorname{sgn}(s))=\left\{\begin{array}{l}
1 \text { if } s<0 \\
0 \text { if } s>0
\end{array}\right.
$$

In [57], a third-order SMC is applied to control the buck converter. The signal triangle is regulated by the input voltage to use with SMC output to generate a signal control to drive the converter, as in Figure 13b. 


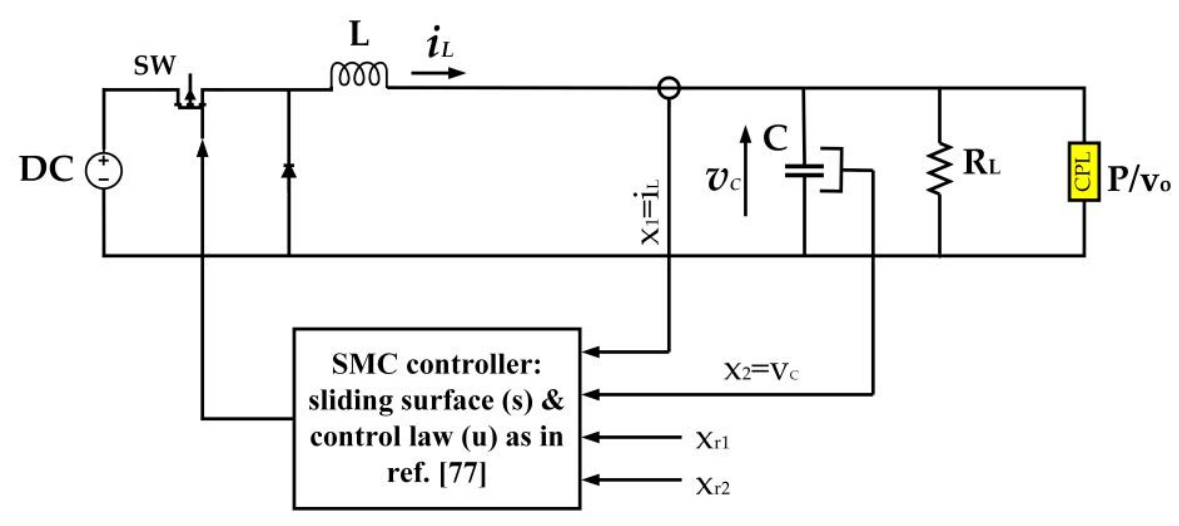

(a)

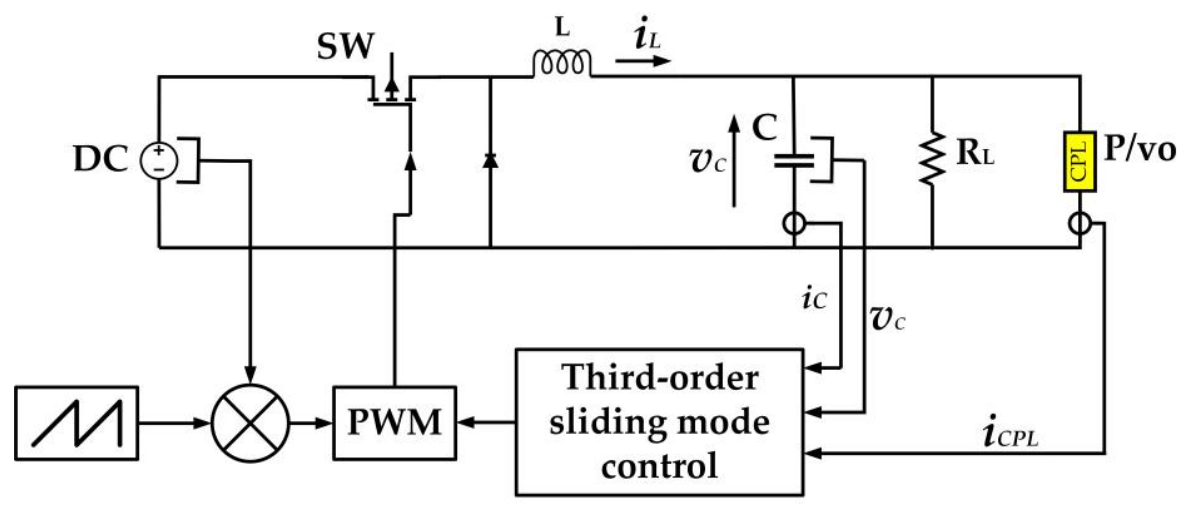

(b)

Figure 13. Sliding mode control with CPL (a) ref. [77]; (b) ref. [57].

\subsection{Model Predictive Control}

In the literature [51,55,83-85], researchers introduced a model predictive control as a solution to mitigate the instability caused by CPL. In [84], a power buffer interfaces between the source converter and CPL to modify the load impedance of during a transient or fault case. The model predictive controller (MPC) controls the variation of the DC link voltage and modifies of the load impedance which is seen at the point of common coupling. In [51], MPC is used with hybrid energy storage to manipulate the energy flows between generator, load, and a hybrid ES which is shown in Figure 14. In $[51,84]$, the MPC is not utilised directly to compensate the instability effects of CPL but in [84] there is introduced an optimal trade-off between modification of load impedance, variation of DC-link voltage and battery current ripples; in [51] this is used to design and/or specify the requirements for the ES to achieve the desired transient response. The required duty cycle of converter is calculated based on MPC strategies to mitigate the instability induced by CPL. The duty cycle configurations are chosen to guarantee the stabilisation of the CPL by associating the CPL current and voltage with the predicted output voltage values of the converter [55]. 


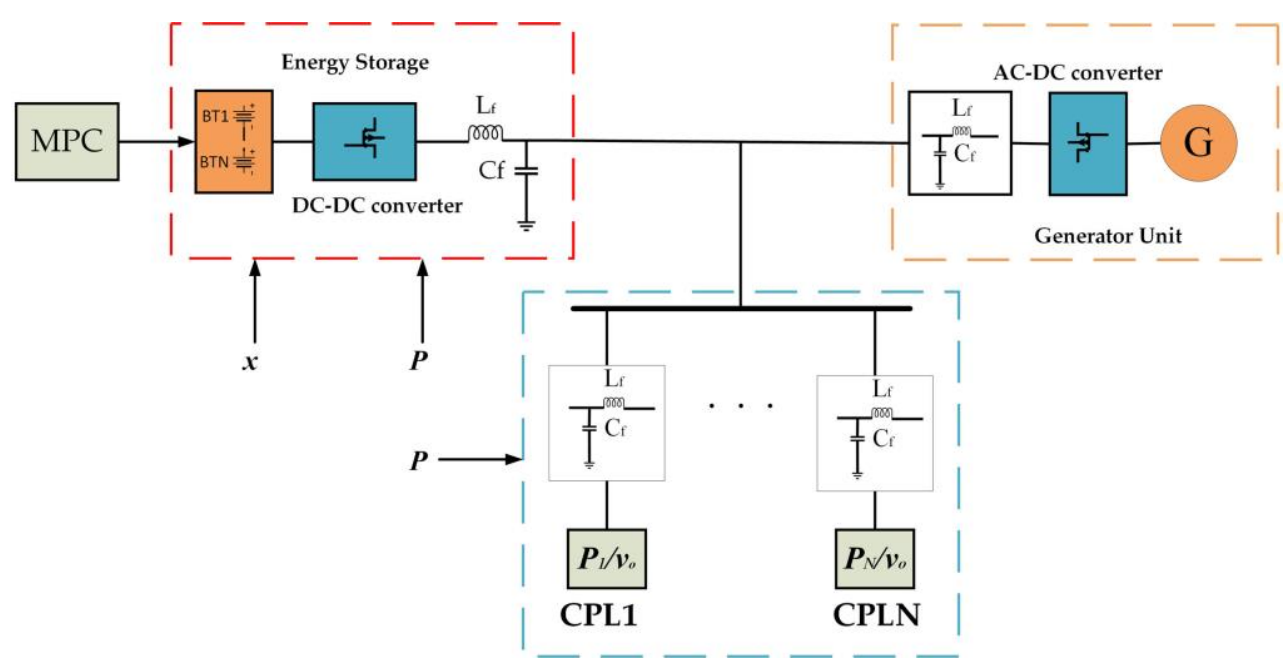

Figure 14. Model predictive control with power buffer.

\subsection{Feedback Linearization}

Feedback linearization is a nonlinear control technique to overcome the instability caused by CPL, as proposed in $[47,52,86-88]$. This technique aims to cancel the nonlinearity introduced by CPL by determining the parameters that can be manipulated to obtain a system without instability without using a conventional PI controller, which has its disadvantages.

In [47], the authors discuss the stability of a DC-DC buck converter that is feeding the resistive load (constant voltage load (CVL)) and CPL as in Figure 15, the large signal stability used, and the stability of system tested by Lyapunov theory. The procedure can be summarised as follows.

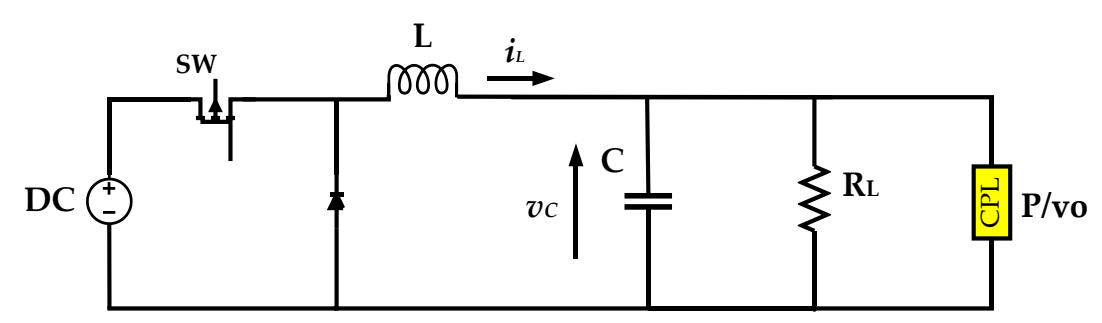

Figure 15. DC-DC buck converter feeding CPL and constant voltage load (CVL).

1- Two differential equations describe the circuit in the Figure 15 as follows:

$$
\begin{gathered}
\frac{d i_{L}}{d t}=\frac{1}{L}\left[d v_{\text {in }}-v_{o}\right] \\
\frac{d v_{C}}{d t}=\frac{1}{C}\left[i_{L}-\frac{v_{O}}{R}-\frac{P}{v_{O}}\right] .
\end{gathered}
$$

2- $\quad$ The paper authors in [47] suggested the change of variables:

$$
\begin{aligned}
& x_{1}=i_{L}-\frac{v_{o}}{R}-\frac{P}{v_{o}} \\
& x_{2}=v_{o}-V_{o R E F}
\end{aligned}
$$

where $V_{O R E F}$ is the reference value for the output voltage of the buck converter. 
3- Rewrite the equations to result in:

$$
\begin{gathered}
\dot{x}_{1}=\frac{d v_{\text {in }}}{L}-\frac{x_{2}+V_{\text {oREF }}}{L}-\frac{x_{1}}{R C}-\frac{P x_{1}}{C\left(x_{2}+V_{\text {oREF }}\right)} \\
\dot{x}_{2}=\frac{x_{1}}{C} .
\end{gathered}
$$

4- Then the following equations were used to cancel out the output nonlinearity in Step 3:

$$
\frac{d v_{i n}}{L}=k_{1} x_{1}-k_{2} x_{2}-\frac{\dot{P} x_{1}}{C\left(x_{2}-V_{o R E F}\right)}+\omega \text { and } \omega=\frac{V_{o R E F}}{L},
$$

where $k_{1}, k_{2}$, and $\dot{P}$ are parameters of the controller to be designed.

5- The equations in Step 4 can be rewritten as

$$
\begin{gathered}
\dot{x}=\left(k_{1}-\frac{1}{R C}\right) x_{1}+\left(k_{2}-\frac{1}{L}\right) x_{2}+\frac{x_{1}}{\left(x_{2}+V_{o R E F}\right)^{2}}(P-\dot{P}) \\
\dot{x}_{2}=\frac{x_{1}}{C} .
\end{gathered}
$$

If $P=\dot{P}$ then the system is linear and $k_{1}, k_{2}$ can be manipulated to put the poles of the system in their proper locations to get a stable system.

In [52] an improvement mothed of feedback linearization [47] cancels the nonlinearity of the system by adding an extra feedback loop that has optimum factor which is named feedback gain $\left(K F B=\left(V_{T r} \cdot \hat{P} \cdot \hat{L}\right) / V_{-} i n\right)$ in Figure 16. This factor is chosen such that $\hat{P}$ and $\hat{L}$ are equal to $P$ and $L$, respectively.

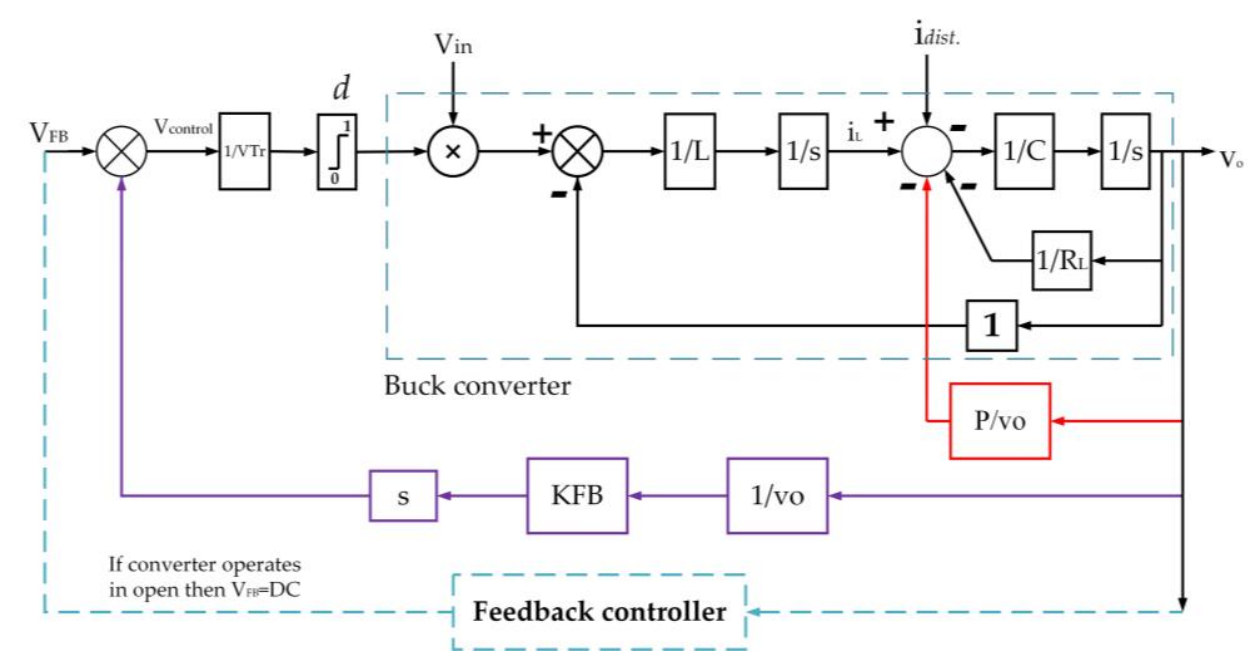

Figure 16. Feedback linearization of buck converter in [52].

Feedback linearization ensures large signal stability and an unlimited value of CPL; however, the drawbacks are low performance and speed $[2,25]$.

\section{Conclusions}

Negative incremental impedance of a constant power load makes a system undergo negative damping and oscillation when a small variation occurs in the load. This phenomenon subjected parts 
of the $\mu$ grid (converters, switches, etc.) to stress and caused voltage collapse or damage to parts of the $\mu$ grid, which might have induced failure.

In this paper we introduce compensation methods that try to make the system stable when it has a constant power load. Many of these methods are aimed at redesigning the feedback of source converter such as feedback linearization, sliding mode control, pulse adjustment control technique, and state pole placement. These have the advantage of not having any effect on the load performance. Other methods were achieved by inserting an auxiliary circuit or power buffer between the source converter and the load converter. However, the auxiliary circuit increases the costs and complexity of the system, and might behave as another CPL in the system.

Author Contributions: All authors contributed for bringing the manuscript in its current state. Their contributions include detailed survey of the literatures and state of art which were essential for the completion of this review paper.

Conflicts of Interest: The authors declare no conflict of interest.

\section{References}

1. Du, W.; Zhang, J.; Zhang, Y.; Qian, Z. Stability criterion for cascaded system with constant power load. IEEE Trans. Power Electron. 2013, 28, 1843-1851. [CrossRef]

2. Singh, S.; Gautam, A.R.; Fulwani, D. Constant power loads and their effects in DC distributed power systems: A review. Renew. Sustain. Energy Rev. 2017, 72, 407-421. [CrossRef]

3. Özsoy, E.; Sanjeevikumar, P.; Mihet-Popa, L.; Fedák, V.; Ahmad, F.; Rasool, A.; Şabanoviç, A. Control strategy for a grid-connected inverter under unbalanced network conditions-A disturbance observer-based decoupled current approach. Energies 2017, 10, 1067. [CrossRef]

4. Chandramohan, K.; Sanjeevikumar, P.; Kalyanasundaram, R.; Bhaskar, M.S.; Mihet-Popa, L. Grid Synchronization of Seven-Phase Wind Electric Generator Using dq PLL. Energies 2017, 10, 926. [CrossRef]

5. Un-Noor, F.; Sanjeevikumar, P.; Mihet-Popa, L.; Mollah, M.N.; Hossain, E. A Comprehensive Study of Key Electric Vehicle (EV) Components, Technologies, Challenges, Impacts, and Future Direction of Development. Energies 2017, 10, 1217. [CrossRef]

6. Singh, S.; Rathore, N.; Fulwani, D. Mitigation of Negative Impedance Instabilities in a DC/DC Buck-Boost Converter with Composite Load. J. Power Electron. 2016, 16, 1046-1055. [CrossRef]

7. Bevrani, H.; Ise, T. Microgrid Dynamics and Control; John Wiley \& Sons: Hoboken, NJ, USA, 2017.

8. Colak, I.; Bayindir, R.; Al-Nussairi, M.; Hossain, E. Voltage and frequency stability analysis of AC microgrid. In Proceedings of the IEEE International Telecommunications Energy Conference (INTELEC), Osaka, Japan, 18-22 October 2015; pp. 1-7.

9. Mihet-Popa, L.; Koch-Ciobotaru, C.; Isleifsson, F.; Bindner, H. Development of tools for DER components in a distribution network. In Proceedings of the XXth International Conference on Electrical Machines (ICEM), Marselle, France, 2-5 September 2012; pp. 2072-2078.

10. Mihet-Popa, L.; Bindner, H. Simulation models developed for voltage control in a distribution network using energy storage systems for PV penetration. In Proceedings of the IECON 2013-39th Annual Conference of the IEEE Industrial Electronics Society, Vienna, Austria, 10-13 November 2013; pp. 7487-7492.

11. Tiwaria, R.; Babu, N.; Sanjeevikumar, P. A Review on GRID CODES-Reactive Power Management in Power Grids for Doubly-Fed Induction Generator in Wind Power Application. In Lecture Notes in Electrical Engineering; Springer: Berlin/Heidelberg, Germany, 2017.

12. Swaminathan, G.; Ramesh, V.; Umashankar, S.; Sanjeevikumar, P. Fuzzy Based micro grid energy management system using interleaved boost converter and three level NPC inverter with improved grid voltage quality. In Lecture Notes in Electrical Engineering; Springer: Berlin/Heidelberg, Germany, 2017.

13. Tamvada, K.; Umashankar, S.; Sanjeevikumar, P. Impact of Power Quality Disturbances on Grid Connected Double Fed Induction Generator. In Lecture Notes in Electrical Engineering; Springer: Berlin/Heidelberg, Germany, 2017.

14. Pouresmaeil, E.; Mehrasa, M.; Shokridehaki, M.A.; Rodrigues, E.; Catalão, J.P.S. Stable operation of distributed generation units in microgrid networks. In Proceedings of the Australasian Universities Power Engineering Conference (AUPEC), Wollongong, Australia, 27-30 September 2015; pp. 1-6. 
15. Mehrasa, M.; Adabi, M.E.; Pouresmaeil, E.; Adabi, J. Passivity-based control technique for integration of DG resources into the power grid. Int. J. Electr. Power Energy Syst. 2014, 58, 281-290. [CrossRef]

16. Mehrasa, M.; Pouresmaeil, E.; Catalão, J.P. Direct Lyapunov control technique for the stable operation of multilevel converter-based distributed generation in power grid. IEEE J. Emerg. Sel. Top. Power Electron. 2014, 2, 931-941. [CrossRef]

17. Mehrasa, M.; Adabi, M.E.; Pouresmaeil, E.; Adabi, J.; Jørgensen, B.N. Direct Lyapunov control (DLC) technique for distributed generation (DG) technology. Electr. Eng. 2014, 96, 309-321. [CrossRef]

18. Ali, A.; Sanjeevikumar, P.; Twala, B.; Marwala, T. Electric Power Grids Distribution Generation System For Optimal Location and Sizing-An Case Study Investigation by Various Optimization Algorithms. Energies 2017, 10, 960 .

19. Camacho, O.M.F.; Norgard, P.B.; Rao, N.; Mihet-Popa, L. Electrical vehicle batteries testing in a distribution network using sustainable energy. IEEE Trans. Smart Grid 2014, 5, 1033-1042. [CrossRef]

20. Mehrasa, M.; Pouresmaeil, E.; Akorede, M.F.; Jørgensen, B.N.; Catalão, J.P. Multilevel converter control approach of active power filter for harmonics elimination in electric grids. Energy 2015, 84, 722-731. [CrossRef]

21. Rivetta, C.; Williamson, G.A.; Emadi, A. Constant power loads and negative impedance instability in sea and undersea vehicles: Statement of the problem and comprehensive large-signal solution. In Proceedings of the IEEE Electric Ship Technologies Symposium, Philadelphia, PA, USA, 27 July 2005; pp. 313-320.

22. Emadi, A.; Khaligh, A.; Rivetta, C.H.; Williamson, G.A. Constant power loads and negative impedance instability in automotive systems: Definition, modeling, stability, and control of power electronic converters and motor drives. IEEE Trans. Veh. Technol. 2006, 55, 1112-1125. [CrossRef]

23. Ghisla, U.; Kondratiev, I.; Dougal, R. Protection of medium voltage DC power systems against ground faults and negative incremental impedances. In Proceedings of the IEEE SoutheastCon 2010 (SoutheastCon), Concord, NC, USA, 18-21 March 2010; pp. 259-263.

24. Luo, S. A review of distributed power systems part I: DC distributed power system. IEEE Aerosp. Electron. Syst. Mag. 2005, 20, 5-16. [CrossRef]

25. Fulwani, D.K.; Singh, S. Mitigation of Negative Impedance Instabilities in DC Distribution Systems: A Sliding Mode Control Approach; Springer: Berlin, Germany, 2016.

26. Lasseter, R.H. Microgrids. In Proceedings of the IEEE Power Engineering Society Winter Meeting, New York, NY, USA, 27-31 January 2002; Volume 1, pp. 305-308.

27. Lasseter, R.; Akhil, A.; Marnay, C.; Stephens, J.; Dagle, J.; Guttromson, R.; Meliopoulos, A.; Yinger, R.; Eto, J. Integration of Distributed Energy Resources: The CERTS MicroGrid Concept. Available online: http:/ / bnrg.eecs.berkeley.edu/ randy/Courses/CS294.F09/MicroGrid.pdf (accessed on 30 August 2017).

28. Martin-Martínez, F.; Sánchez-Miralles, A.; Rivier, M. A literature review of Microgrids: A functional layer based classification. Renew. Sustain. Energy Rev. 2016, 62, 1133-1153. [CrossRef]

29. Hatziargyriou, N. Microgrids: Architectures and Control; John Wiley \& Sons: Hoboken, NJ, USA, 2013.

30. Lenz, E.; Pagano, D.J. Nonlinear control of a three-phase power converter with constant power load in a microgrid. In Proceedings of the IEEE Brazilian Power Electronics Conference, Gramado, Brazil, 27-31 October 2013; pp. 368-373.

31. Peng, F.Z.; Li, Y.W.; Tolbert, L.M. Control and protection of power electronics interfaced distributed generation systems in a customer-driven microgrid. In Proceedings of the IEEE Power \& Energy Society General Meeting, Calgary, AB, Canada, 26-30 July 2009; pp. 1-8.

32. Ganesan, S.; Sanjeevikumar, P.; Varadarajan, R.; Subramaniam, U.; Mihet-Popa, L. Study and Analysis of an Intelligent Microgrid Energy Management Solution with Distributed Energy Sources. Energies 2017, 10, 1419. [CrossRef]

33. Fan, L. Control and Dynamics in Power Systems and Microgrids; CRC Press: Boca Raton, FL, USA, 2017.

34. Lu, X.; Sun, K.; Huang, L.; Guerrero, J.M.; Vasquez, J.C.; Xing, Y. Virtual impedance based stability improvement for DC microgrids with constant power loads. In Proceedings of the IEEE Energy Conversion Congress and Exposition (ECCE), Pittsburgh, PA, USA, 14-18 September 2014; pp. 2670-2675.

35. Vavilapalli, S.; Sanjeevikumar, P.; Subramaniam, U.; Mihet-Popa, L. Power Balancing Control for Grid Energy Storage System in PV Applications—Real Time Digital Simulation Implementation. Energies 2017, 10, 928. [CrossRef] 
36. Emadi, A.; Fahimi, B.; Ehsani, M. On the concept of negative impedance instability in the more electric aircraft power systems with constant power loads. SAE Tech. Pap. 1999. [CrossRef]

37. Emadi, A.; Ehsani, M.; Miller, J.M. Vehicular Electric Power Systems: Land, Sea, Air, and Space Vehicles; CRC Press: Boca Raton, FL, USA, 2003.

38. Emadi, A.; Ehsani, M. Multi-converter power electronic systems: Definition and applications. In Proceedings of the IEEE 32nd Annual Power Electronics Specialists Conference (PESC), Vancouver, BC, Canada, 17-21 June 2001; Volume 2, pp. 1230-1236.

39. Céspedes, M.; Beechner, T.; Xing, L.; Sun, J. Stabilization of constant-power loads by passive impedance damping. In Proceedings of the Twenty-Fifth Annual IEEE Applied Power Electronics Conference and Exposition (APEC), Palm Springs, CA, USA, 21-25 February 2010; pp. 2174-2180.

40. Zhang, F.; Yan, Y. Start-up process and step response of a DC-DC converter loaded by constant power loads. IEEE Trans. Ind. Electron. 2011, 58, 298-304. [CrossRef]

41. Jusoh, A.B. The instability effect of constant power loads. In Proceedings of the National Power and Energy Conference, Kuala Lumpur, Malaysia, 29-30 November 2004; pp. 175-179.

42. Khaligh, A.; Emadi, A.; Williamson, G.A.; Rivetta, C. Constant power load characteristics in multi-converter automotive power electronic intensive systems. SAE Tech. Pap. 2005. [CrossRef]

43. Khaligh, A.; Emadi, A. Power alignment, new digital control approach for a DC-DC flyback converter with constant power loads. In Proceedings of the 1ST IEEE Conference on Industrial Electronics and Applications, Singapore, 24-26 May 2006; pp. 1-6.

44. Belkhayat, M. Stability Criteria for ac Power Systems with Regulated Loads; Purdue University: West Lafayette, IN, USA, 1997.

45. Vilathgamuwa, D.; Zhang, X.; Jayasinghe, S.; Bhangu, B.; Gajanayake, C.; Tseng, K.J. Virtual resistance based active damping solution for constant power instability in AC microgrids. In Proceedings of the IECON 2011-37th Annual Conference on IEEE Industrial Electronics Society, Melbourne, Australia, 7-10 November 2011; pp. 3646-3651.

46. Rahimi, A.M.; Emadi, A. Discontinuous-conduction mode DC/DC converters feeding constant-power loads. IEEE Trans. Ind. Electron. 2010, 57, 1318-1329. [CrossRef]

47. Emadi, A.; Ehsani, M. Negative impedance stabilizing controls for PWM DC-DC converters using feedback linearization techniques. In Proceedings of the (IECEC) 35th Intersociety Energy Conversion Engineering Conference and Exhibit, Las Vegas, NV, USA, 24-28 July 2000; Volume 1, pp. 613-620.

48. Khaligh, A.; Rahimi, A.M.; Chakraborty, A.; Emadi, A. Analysis and stabilization of a Buck-Boost DC-DC converter feeding constant power loads in parallel with conventional loads in vehicular systems. In Proceedings of the IECON 2006-32nd Annual Conference on IEEE Industrial Electronics, Paris, France, 6-10 November 2006; pp. 2799-2804.

49. Kim, S.; Williamson, S.S. Negative impedance instability compensation in more electric aircraft DC power systems using state space pole placement control. In Proceedings of the IEEE Vehicle Power and Propulsion Conference (VPPC), Chicago, IL, USA, 6-9 September 2011; pp. 1-6.

50. Liu, X.; Zhou, Y.; Zhang, W.; Ma, S. Stability criteria for constant power loads with multistage \$ LC \$ filters. IEEE Trans. Veh. Technol. 2011, 60, 2042-2049. [CrossRef]

51. Herrera, L.C.; Tsao, B.-H. Analysis and Control of Energy Storage in Aircraft Power Systems with Pulsed Power Loads. SAE Int. J. Aerosp. 2016, 9, 8-13. [CrossRef]

52. Rahimi, A.M.; Williamson, G.A.; Emadi, A. Loop-cancellation technique: A novel nonlinear feedback to overcome the destabilizing effect of constant-power loads. IEEE Trans. Veh. Technol. 2010, 59, 650-661. [CrossRef]

53. Belkhayat, M.; Cooley, R.; Witulski, A. Large signal stability criteria for distributed systems with constant power loads. In Proceedings of the 26th Annual IEEE Power Electronics Specialists Conference, Atlanta, GA, USA, 18-22 June 1995; Volume 2, pp. 1333-1338.

54. Wu, M.; Lu, D.D. Adding virtual resistance in source side converters for stabilization of cascaded connected two stage converter systems with constant power loads in dc microgrids. In Proceedings of the International Power Electronics Conference (IPEC-Hiroshima 2014-ECCE-ASIA), Hiroshima, Japan, 18-21 May 2014; pp. 3553-3556. 
55. Mahmoudi, H.; Aleenejad, M.; Ahmadi, R. A new Modulated Model Predictive Control method for mitigation of effects of constant power loads. In Proceedings of the IEEE Power and Energy Conference at Illinois (PECI), Urbana, IL, USA, 19-20 February 2016; pp. 1-5.

56. Khaligh, A.; Emadi, A. Mixed DCM/CCM pulse adjustment with constant power loads. IEEE Trans. Aerosp. Electron. Syst. 2008, 44. [CrossRef]

57. Zhao, Y.; Qiao, W. A Third-Order Sliding-Mode Controller for DCmC Converters with Constant Power Loads. In Proceedings of the IEEE Industry Applications Society Annual Meeting (IAS), Orlando, FL, USA, 9-13 October 2011.

58. Mingfei, W.; Lu, D.D.-C. Active stabilization methods of electric power systems with constant power loads: A review. J. Modern Power Syst. Clean Energy 2014, 2, 233-243.

59. Cespedes, M.; Xing, L.; Sun, J. Constant-power load system stabilization by passive damping. IEEE Trans. Power Electron. 2011, 26, 1832-1836. [CrossRef]

60. Liu, X.; Ma, S. Large signal stabilization method of constant power loads by adding R parallel damping filters. In Proceedings of the IEEE Energy Conversion Congress and Exposition (ECCE), Montreal, QC, Canada, 20-24 September 2015; pp. 1314-1319.

61. Khaligh, A. Realization of parasitics in stability of DC-DC converters loaded by constant power loads in advanced multiconverter automotive systems. IEEE Trans. Ind. Electron. 2008, 55, 2295-2305. [CrossRef]

62. Khaligh, A.; Chapman, P.; Davoudi, A.; Jatskevich, J. Realization of Parasitics in the Stability of Dc-Dc Converters Loaded by Constant-Power Loads in Discontinuous Conduction Mode. In Proceedings of the IEEE Vehicle Power and Propulsion Conference, Arlington, TX, USA, 9-12 September 2007; pp. 31-35.

63. Rahimi, A.M.; Emadi, A. Active damping in dc/dc power electronic converters: A novel method to overcome the problems of constant power loads. IEEE Trans. Ind. Electron. 2009, 56, 1428-1439. [CrossRef]

64. Wu, M.; Lu, D.D.-C. An active damping method for stabilization of cascaded connected two stage converter systems with constant power loads in DC microgrids. In Proceedings of the IEEE International Symposium on Circuits and Systems (ISCAS), Melbourne, Australia, 1-5 June 2014; pp. 2664-2667.

65. Lu, X.; Sun, K.; Guerrero, J.M.; Vasquez, J.C.; Huang, L.; Wang, J. Stability enhancement based on virtual impedance for DC microgrids with constant power loads. IEEE Trans. Smart Grid 2015, 6, 2770-2783. [CrossRef]

66. Cai, W.; Fahimi, B.; Cosoroaba, E.; Yi, F. Stability analysis and voltage control method based on virtual resistor and proportional voltage feedback loop for cascaded dc-dc converters. In Proceedings of the IEEE Energy Conversion Congress and Exposition (ECCE), Pittsburgh, PA, USA, 14-18 September 2014; pp. 3016-3022.

67. Hu, H.; Wang, X.; Peng, Y.; Xia, Y.; Yu, M.; Wei, W. Stability Analysis and Stability Enhancement Based on Virtual Harmonic Resistance for Meshed DC Distributed Power Systems with Constant Power Loads. Energies 2017, 10, 69. [CrossRef]

68. Wu, M.; Lu, D.D.-C. A novel stabilization method of LC input filter with constant power loads without load performance compromise in DC microgrids. IEEE Trans. Ind. Electron. 2015, 62, 4552-4562. [CrossRef]

69. Zhang, P.; Wen, X.; Liu, J. Feed-forward control for stability improvement in cascaded system. In Proceedings of the International Conference on Electrical and Control Engineering (ICECE), Wuhan, China, 25-27 June 2010; pp. 3746-3749.

70. Ashourloo, M.; Khorsandi, A.; Mokhtari, H. Stabilization of DC microgrids with constant-power loads by an active damping method. In Proceedings of the 4th Power Electronics, Drive Systems and Technologies Conference (PEDSTC), Tehran, Iran, 13-14 February 2013; pp. 471-475.

71. Liu, X.; Forsyth, A.J.; Cross, A.M. Negative input-resistance compensator for a constant power load. IEEE Trans. Ind. Electron. 2007, 54, 3188-3196. [CrossRef]

72. Liu, X.; Fournier, N.; Forsyth, A.J. Active stabilisation of an HVDC distribution system with multiple constant power loads. In Proceedings of the VPPC'08 IEEE Vehicle Power and Propulsion Conference, Harbin, China, 3-5 September 2008; pp. 1-6.

73. Magne, P.; Nahid-Mobarakeh, B.; Pierfederici, S. Active stabilization of dc microgrids without remote sensors for more electric aircraft. IEEE Trans. Ind. Appl. 2013, 49, 2352-2360. [CrossRef]

74. Khaligh, A.; Rahimi, A.M.; Emadi, A. Negative impedance stabilizing pulse adjustment control technique for DC/DC converters operating in discontinuous conduction mode and driving constant power loads. IEEE Trans. Veh. Technol. 2007, 56, 2005-2016. [CrossRef] 
75. Rahimi, A.M. Addressing Negative Impedance Instability Problem of Constant Power Loads: Comprehensive View Encompassing Entire System from the Load to the Source; Illinois Institute of Technology: Chicago, IL, USA, 2008.

76. Zhao, Y.; Qiao, W.; Ha, D. A sliding-mode duty-ratio controller for dc/dc buck converters with constant power loads. IEEE Trans. Ind. Appl. 2014, 50, 1448-1458. [CrossRef]

77. Singh, S.; Fulwani, D. Voltage regulation and stabilization of dc/dc buck converter under constant power loading. In Proceedings of the IEEE International Conference on Power Electronics, Drives and Energy Systems (PEDES), Mumbai, India, 16-19 December 2014; pp. 1-6.

78. Singh, S.; Fulwani, D. Constant power loads: A solution using sliding mode control. In Proceedings of the IECON 2014-40th Annual Conference of the IEEE Industrial Electronics Society, Dallas, TX, USA, 29 October-1 November 2014; pp. 1989-1995.

79. Singh, S.; Fulwani, D. A PWM based sliding-mode control for negative impedance stabilization in DC Micro-girds. In Proceedings of the 6th IEEE Power India International Conference (PIICON), Delhi, India, 5-7 December 2014; pp. 1-6.

80. Agarwal, A.; Deekshitha, K.; Singh, S.; Fulwani, D. Sliding mode control of a bidirectional DC/DC converter with constant power load. In Proceedings of the IEEE First International Conference on DC Microgrids (ICDCM), Atlanta, GA, USA, 7-10 June 2015; pp. 287-292.

81. Singh, S.; Fulwani, D.; Kumar, V. Robust sliding-mode control of DC/DC boost converter feeding a constant power load. IET Power Electron. 2015, 8, 1230-1237. [CrossRef]

82. Hossain, E.; Perez, R.; Sanjeevikumar, P.; Siano, P. Investigation on Development of Sliding Mode Controller for Constant Power Loads in Microgrids. Energies 2017, 10, 1086. [CrossRef]

83. Neely, J.; Pekarek, S.; DeCarlo, R.; Vaks, N. Real-time hybrid model predictive control of a boost converter with constant power load. In Proceedings of the Twenty-Fifth Annual IEEE Applied Power Electronics Conference and Exposition (APEC), Palm Springs, CA, USA, 21-25 February 2010; pp. 480-490.

84. Zhang, X.; Vilathgamuwa, D.M.; Tseng, K.-J.; Bhangu, B.S.; Gajanayake, C.J. Power buffer with model predictive control for stability of vehicular power systems with constant power loads. IEEE Trans. Power Electron. 2013, 28, 5804-5812. [CrossRef]

85. Zong, Y.; Mihet-Popa, L.; Kullman, D.; Thavlov, A.; Gehrke, O.; Bindner, H. Model Predictive Controller for Active Demand Side Management with PV Self-Consumption in an Intelligent Building. In Proceedings of the IEEE PES Innovative Smart Grid Technologies Europe, Berlin, Germany, 14-17 October 2012.

86. Ciezki, J.; Ashton, R. The application of feedback linearization techniques to the stabilization of DC-to-DC converters with constant power loads. In Proceedings of the 1998 IEEE International Symposium on Circuits and Systems, Monterey, CA, USA, 31 May-3 June 1998; Volume 3, pp. 526-529.

87. Solsona, J.A.; Jorge, S.G.; Busada, C.A. Nonlinear control of a buck converter which feeds a constant power load. IEEE Trans. Power Electron. 2015, 30, 7193-7201. [CrossRef]

88. Sulligoi, G.; Bosich, D.; Giadrossi, G.; Zhu, L.; Cupelli, M.; Monti, A. Multiconverter medium voltage DC power systems on ships: Constant-power loads instability solution using linearization via state feedback control. IEEE Trans. Smart Grid 2014, 5, 2543-2552. [CrossRef]

(C) 2017 by the authors. Licensee MDPI, Basel, Switzerland. This article is an open access article distributed under the terms and conditions of the Creative Commons Attribution (CC BY) license (http://creativecommons.org/licenses/by/4.0/). 